\title{
Space Leaky Waves Propagating along a Pair of CRLH SIW Lines
}

\author{
Rihem NOUMI ${ }^{1}$, Jan MACHAC ${ }^{2}$, Ali GHARSALLAH ${ }^{1}$ \\ ${ }^{1}$ Dept. of Physics, Faculty of Sciences of Tunis, University of Tunis El Manar, 2092, Tunis, Tunisia \\ ${ }^{2}$ Dept. of Electromagnetic Field, Faculty of Electrical Engineering, Czech Technical University in Prague, Technicka 2, \\ 16627 Prague 6, Czech Republic \\ noumii.rihem@gmail.com
}

Submitted January 4, 2018 / Accepted July 17, 2018

\begin{abstract}
A space leaky wave excited on composite rightleft handed substrate integrated waveguide and radiating in a wide frequency band is presented in this paper. The proposed two line array is a good candidate for smart systems of monitoring and tracking applications. The system is composed of two different lines that are placed in parallel on the same substrate. Simulation results show that the first line leaks energy in the band from 6.9 to $11 \mathrm{GHz}$ with a $7.8 \mathrm{GHz}$ broadside radiation frequency and the second line leaks in the band from 8.9 to $13.8 \mathrm{GHz}$; the related broadside radiation frequency is $10.2 \mathrm{GHz}$. Complex single/dual scanned beams are obtained in a wide range of angles from $-72^{\circ}$ to $+73^{\circ}$. The simulations were carried out in the CST Microwave Studio and the obtained measurement results match well with the theoretical analysis described in this paper.
\end{abstract}

\section{Keywords}

Space leaky wave, substrate integrated waveguide, composite right-left handed line

\section{Introduction}

Since the advent of substrate integrated waveguide (SIW) in the microwave engineering society, many researchers have rapidly valued the importance of this technology thanks to its minimal loss, ease of fabrication, low cost and small size compared to the rectangular waveguide [1-4].

In recent years, leakage of energy from SIW has been widely studied for its outstanding advantages related to the continuous beam steering of the leaky field distribution. Several works were focused on the design of dual-beam leaky wave antennas [5-8]. They are preferred for both their low profiles and loss and also mainly for their scanning flexibility especially for the systems that require multiple coverage of spaces. This work investigates the propagation of space leaky wave along SIW CRLH transmission line. In the case of a single line, the behavior of the space leaky wave is well known, see e.g. [9], [10]. A complex phenomenon has been revealed in the case of a pair of the CRLH SIW transmission lines designed on a common substrate. These two lines are tuned to different frequencies. In this case, the two transmission lines are fed into opposite terminals. The remaining terminals are matched. The field radiated by the pair of space leaky waves depends strongly on the phase shift between feeding signals. When the phase shift is equal to $180^{\circ}$, the radiated field offers two main beams at most frequencies. The broadside radiation which is perpendicular to the lines' direction appears at the original frequencies of the particular waves.

The proposed pair of transmission lines can scan both single and double beams depending on the frequency range, corresponding to a beam of the first antenna (or the second one) and two simultaneous beams from both lines, respectively. This beam steering is obtained from $-72^{\circ}$ to $73^{\circ}$ with reaching broadside radiation at 7.8 and $10.2 \mathrm{GHz}$. Furthermore, the current design features an asymmetric dual beam scanning and operates in a wide frequency bandwidth from $6.9 \mathrm{GHz}$ to $13.5 \mathrm{GHz}$. The work presented in this paper illustrates a complex behavior of leakage from open transmission lines. This design can be an attractive feature for smart protecting systems that are used in a complex space geometry and for scanning systems and tracking applications.

\section{Theory: Leakage from SIW Lines}

The leaky wave propagates along a transmission line as the mode with a complex propagation constant $k_{\mathrm{z}}[10]$ :

$$
k_{\mathrm{z}}=\beta-\mathrm{j} \alpha .
$$

There are two kinds of leaky waves, distinguished by the relation of their phase constant $\beta$ to the propagation constant in a surrounding medium. The substrate leaky wave mode fulfills the phase condition for $\beta<k_{\mathrm{TM}}$ (or $k_{\mathrm{TE}}$ ) where $k_{\mathrm{TM}}$ or $k_{\mathrm{TE}}$ are phase constants of the corresponding surface wave propagating in a substrate. Space leaky wave 
(propagating along open transmission line) fulfills the phase condition $\beta<k_{0}$ where $k_{0}$ is the free space propagation constant. Space leaky wave radiates power from the transmission line into the space above it. Now $\beta$ controls the radiated beam angle, and $\alpha$ is the leakage rate which controls the beam width [11]. Theoretically, the space leaky wave field increases to infinity in a perpendicular direction to the line substrate. The real radiated field must fulfill the radiation condition in infinity. Therefore, after reaching its maximum at the approximate direction determined by the $\theta$ angle, the field decreases again to meet the radiation condition

$$
\cos \left(\theta_{\max }\right)=\frac{\beta}{k_{0}}
$$

The phase constant is positive in the case of a standard transmission line. In this instance, the field is radiated only in a forward direction as e.g. in [12]. The composite rightleft handed (CRLH) line substantially improves the radiation and therefore the line applicability. The phase constant can be negative as well as positive. Hence, the space leaky wave radiates depending on frequency both in the backward and forward directions. The current of this wave can be approximated by a simple function

$$
I(z)=I_{0} \exp \left(-\mathrm{j} k_{\mathrm{z}} z\right)=I_{0} \exp (-\alpha z) \exp (-\mathrm{j} \beta z) .
$$

The wave propagates along the line and leaks power to the space and therefore its amplitude decreases along the line. Due to the leakage caused by such a wave, the radiation pattern can simply be calculated by [11]

$$
E_{\theta 1}=I_{1} \frac{\mathrm{j} \omega \mu_{0}}{4 \pi r} \exp \left(-\mathrm{j} k_{0} r\right) \sin \theta \int_{0}^{L} \exp \left[-\mathrm{j} k_{\mathrm{z} 1} \cos \left(\theta z^{\prime}\right)\right] \mathrm{d} z^{\prime}
$$

$I_{1}$ is the current amplitude at the feeding point at $z=0$. Depending on the phase constant sign, a leakage in backward or forward directions was obtained.

The proposed structure is composed of an array of two CRLH SIW lines positioned along the $z$-axis as shown in Fig. 1. The two lines have different frequencies of the broadside radiation at which the phase constant is zero. The lengths of their unit cells must be equal as the lines must have the same length. For analysis purposes, coupling between the two lines is considered to be negligible. The total radiated field of the two SIW lines is given by

$$
E_{\theta \text { total }}=E_{\theta 1}+E_{\theta 2} \exp (\mathrm{j} \varphi)
$$

with $E_{\theta 1}$ determined by (4), and similarly with

$$
\begin{aligned}
& E_{\theta 2}= \\
& I_{2} \frac{\mathrm{j} \omega \mu_{0}}{4 \pi r} \exp \left(-\mathrm{j} k_{0} r\right) \exp (\mathrm{j} \varphi) \sin \theta \int_{0}^{L} \exp \left[-\mathrm{j} k_{\mathrm{z} 2} \cos \left(\theta z^{\prime \prime}\right)\right] \mathrm{d} z^{\prime \prime}
\end{aligned}
$$

where the phase $\varphi$ shift between the two feeding ports is equal to $180^{\circ}, L$ is the length of the leaky wave CRLH line structure, $E_{\theta 1}$ is the radiated field of the first CRLH SIW

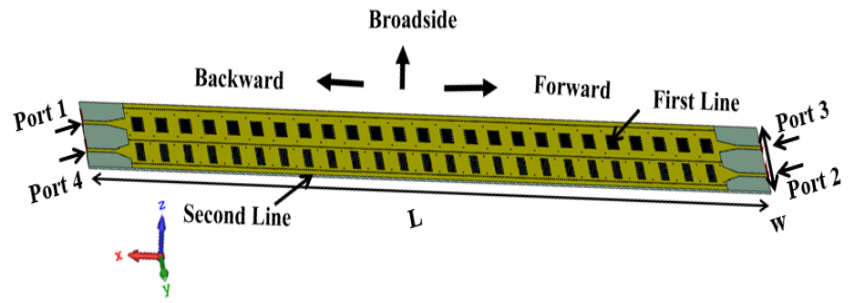

Fig. 1. Layout of the array of the two CRLH SIW lines. The dimensions are: $L=205 \mathrm{~mm}$ and $W=29.3 \mathrm{~mm}$ : the input ports with opposite phase of $\varphi=180^{\circ}$ are port 1 and port 2. Port 3 and port 4 are matched by $50 \Omega$ loads. Direction characteristics (backward, broadside, forward) are shown.

line, $E_{\theta 2}$ is the radiated field of the second CRLH SIW line and $k_{\mathrm{z} 1}$ and $k_{\mathrm{z} 2}$ are the complex propagation constants of the first and the second lines, respectively. The integration of (4) and (6) gives the following radiated field formulas

$$
\begin{aligned}
E_{\theta 1}= & I_{1} \frac{\mathrm{j} \omega \mu_{0}}{4 \pi r} \exp \left(-\mathrm{j} k_{0} r\right) \sin \theta . \\
& \left\{\frac{\exp \left[\mathrm{j} L\left(k_{0} \cos \theta\right) \exp \left(-\mathrm{j} L\left(\beta_{1}-\mathrm{j} \alpha_{1}\right)\right)\right]-1}{\mathrm{j}\left(k_{0} \cos \theta-\left(\beta_{1}-\mathrm{j} \alpha_{1}\right)\right)}\right\}, \\
E_{\theta 2}= & I_{2} \frac{\mathrm{j} \omega \mu_{0}}{4 \pi r} \exp \left(-\mathrm{j} k_{0} r\right) \sin \theta . \\
& \left\{\frac{\exp \left[\mathrm{j} L\left(k_{0} \cos \theta\right) \exp \left(-\mathrm{j} L\left(\beta_{2}-\mathrm{j} \alpha_{2}\right)\right)\right]-1}{\mathrm{j}\left(k_{0} \cos \theta-\left(\beta_{2}-\mathrm{j} \alpha_{2}\right)\right)}\right\} .
\end{aligned}
$$

\section{Proposed Structure of Transmission Lines}

The proposed prototype of the two parallel CRLH SIW transmission lines that are shown in Fig. 1 has been designed to verify the scanning process of the two space leaky wave superposition. The lines radiate through periodic inter-digital capacitor slots etched on the upper face of the SIW. Rogers' substrate 5880 with a relative permittivity of 2.2 and a thickness of $0.508 \mathrm{~mm}$ is used. The lines are fed via two input ports at opposite ends which are excited simultaneously with a phase shift, among them $\varphi=180^{\circ}$.

As the first step of the design, two different SIW CRLH cells operating in different frequency bands are considered. The two lines are designed to be in the balance case, i.e. without a stop band. The frequencies of broadside radiation $(\beta=0)$ are located at $7.8 \mathrm{GHz}$ and $10.2 \mathrm{GHz}$ for the first and second cells, respectively. The corresponding cell layouts are shown in Fig. 2. The side walls of these models are made-up by solid PEC walls to simplify the simulation process. An inter-digital slot etched on the upper face of the SIW cells serves as a series capacitor. In addition, two inductance pins are inserted into the left side of each unit cell. The distance between these two pins is an important factor allowing the reduction of the stop band, and a balanced state is obtained by optimizing the value of 


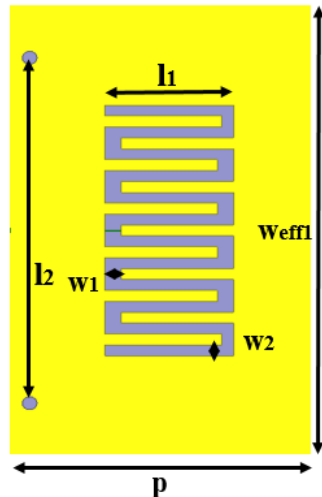

(a)

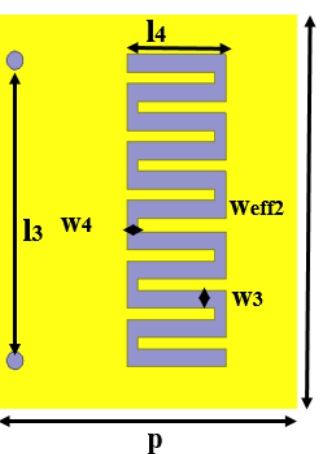

(b)
Fig. 2. Unit cell of the proposed CRLH SIW lines: (a) Unit cell of the first CRLH line. (b) Unit cell of the second CRLH line. Dimensions are given in Tab. 1.

\begin{tabular}{|c|c|c|c|c|c|c|}
\hline Parameters & $\mathbf{p}$ & $\boldsymbol{l}_{\mathbf{1}}$ & $\boldsymbol{l}_{\mathbf{2}}$ & $\boldsymbol{w}_{\mathbf{1}}$ & $\boldsymbol{w}_{\mathbf{2}}$ & $\boldsymbol{w}_{\text {eff }}$ \\
\hline Value (mm) & 8.2 & 4 & 6.4 & 0.45 & 0.33 & 11.2 \\
\hline Parameters & $\boldsymbol{w}_{\text {eff1 }}$ & $\boldsymbol{l}_{\mathbf{3}}$ & $\boldsymbol{l}_{\mathbf{4}}$ & $\boldsymbol{w}_{\mathbf{3}}$ & $\boldsymbol{w}_{\mathbf{4}}$ & \\
\cline { 1 - 6 } Value (mm) & 15 & 7.7 & 2.7 & 0.45 & 0.33 & \\
\hline
\end{tabular}

Tab. 1. Dimensions of the proposed unit cell.

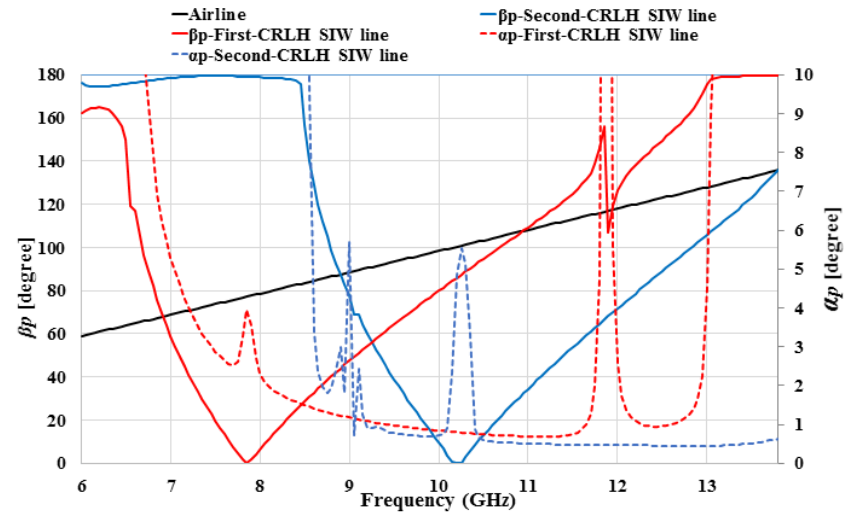

Fig. 3. Dispersion diagrams for the first and the second CRLH SIW unit cells shown in Fig. 2.

this distance. This type of the SIW CRLH TL single cell and its theoretical background have already been reported in [9], [10]. The dimensions of the two different transmission lines are listed in Tab. 1.

The beam scanning range and corresponding frequency bands can be estimated from dispersion relations of the two CRLH SIW unit cells as well as from the $k_{0}$ airline which defines the leakage region $\left(\beta<k_{0}\right)$. Observed results show that the two cells are balanced. The LH region of the first line is given by the band $6.9-7.8 \mathrm{GHz}$ and the $\mathrm{RH}$ region band is among $7.8-11 \mathrm{GHz}$. For the second line, the LH region band is given from 8.9 to $10.2 \mathrm{GHz}$ whereas the $\mathrm{RH}$ region band is set from 10.2 to $13.8 \mathrm{GHz}$. The new phenomena presented by this design show that the space leaky waves can propagate simultaneously along the two lines from 8.9 until $10.2 \mathrm{GHz}$ with $\beta_{1}>0$ and $\beta_{2}<0$ and from 10.2 to $11 \mathrm{GHz}$ with $\beta_{1}>0$ and $\beta_{2}>0$. However, for the first line, a narrow stop band appears around $11.8 \mathrm{GHz}$. This can be explained by the appearance of a parasitic resonance attained from the inter-digital fingers [13].
As mentioned previously, the unit cells are constructed using PEC side walls. In order to include the SIW vias in the design, the physical parameters of the SIW are valued as follows: the effective width $w_{\text {siw }}$ is calculated from a good estimation of the $w_{\text {rec }} / w_{\text {siw }}$ relation defined in [14]. The values of the $d$ diameter of the vias and the $s$ distance between two consecutive vias are calculated from (9) and (10) [15], [16]:

$$
\begin{gathered}
d<\lambda_{\mathrm{g}} / 5, \\
s \leq 2 d
\end{gathered}
$$

where $\lambda_{\mathrm{g}}$ is the guided wavelength along the SIW.

In the final optimum design, the two parallel SIW lines are located on a common substrate, each consisting of 25 unit cells of the same length. Tapered microstrip-toSIW transitions are used to power the considered structure. In addition, the distance between the two lines was optimized to verify the coupling between the feeding ports. Results show that only one row of SIW pins is sufficient to neglect the coupling, as illustrated in Fig. 1. The final parameters of the pair CRLH SIW lines are listed in Tab. 2.

The influence of the $\varphi$ phase difference between feeding port signals to the field distribution is documented in Fig. 4. Here, the field distribution calculated by (7) and (8) shows that a single beam at $9.2 \mathrm{GHz}$ can be acquired only when $\varphi=180^{\circ}$. The aim is to get one beam that is narrower than the two beams at other frequencies. This single beam radiates more effectively. It is shown by the plot in Fig. 4 calculated at the frequency $9.2 \mathrm{GHz}$.

The field distribution of space leaky waves was calculated by (5), (7), and (8). The values of $k_{\mathrm{z} 1}$ and $k_{\mathrm{z} 2}$ are taken from the dispersion relations of the first and second SIW CRLH unit cells plotted in Fig. 3. Figure 5 summarizes the analytical development of the steering behavior over the frequency of the main beam directions produced by leaky waves with the phase difference $\varphi$ equal to $180^{\circ}$. The measured results are also plotted in Fig. 5. The steering range is given from $-72^{\circ}$ to $+73^{\circ}$ in the frequency band

\begin{tabular}{|c|c|c|c|c|c|}
\hline Parameters & $\mathbf{L}$ & $\boldsymbol{d}$ & $\mathbf{s}$ & $\boldsymbol{w}_{\text {siw1 }}$ & $\boldsymbol{w}_{\text {siw2 }}$ \\
\hline Value (mm) & 205 & 0.4 & 0.7 & 14.43 & 10.59 \\
\hline
\end{tabular}

Tab. 2. Dimensions of the proposed structure.

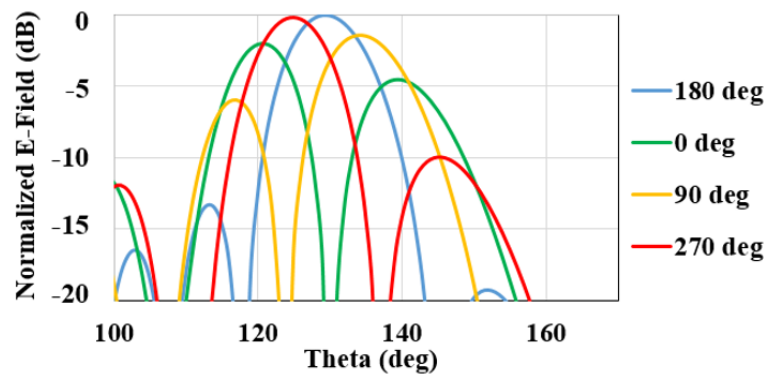

Fig. 4. Analytical results of a normalized E-field distribution calculated by (7) and (8) in dependence on phase difference $\varphi$ at $9.2 \mathrm{GHz}$. 


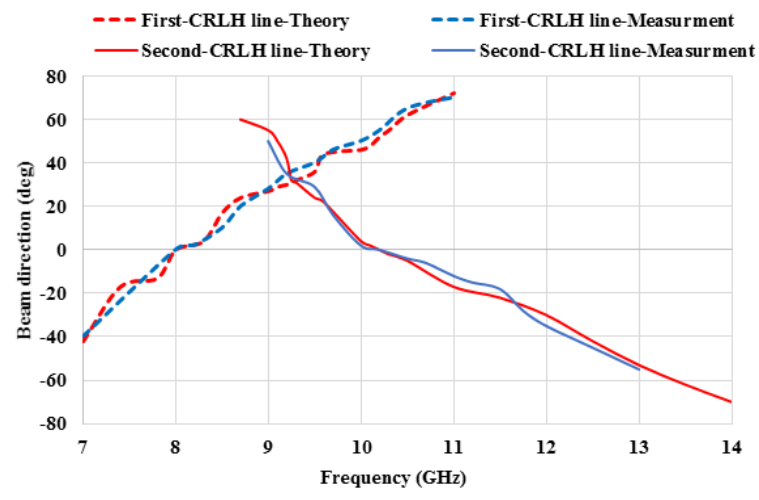

Fig. 5. Measured and theoretical analysis results of main beam directions of the two leaky waves excited on the two parallel CRLH SIW lines.

from 7 to $13.5 \mathrm{GHz}$. More precisely, the observed results demonstrate that from $7 \mathrm{GHz}$ to $8.7 \mathrm{GHz}$ only the wave that is travelling along the first line radiates. In the band 8.8-11 GHz, the pair of transmission lines radiates together two asymmetrical beams, and finally, from 11 until 13.5 GHz, only the wave travelling along the second transmission line radiates.

\section{Simulated and Experimental Results and Discussion}

The prototype of the CRLH SIW two line array designed in Sec. 2 has been fabricated. Figure 6 shows the photograph of the fabricated structure. The lines are fed via two input SMA ports at opposite ends excited simultaneously with phase shift between them $\varphi=180^{\circ}$.

The isolation between ports $S_{21}$ and $S_{41}$ is presented in Fig. 7. It can be observed that the coupling between the ports is significant since the isolation is kept bellow $-20 \mathrm{~dB}$. Scattering parameters were measured by the Rohde \& Schwarz ZV 67 vector network analyzer. Figure 8 shows the simulated and measured results. As previously mentioned, the system was designed carefully to get unit cells balanced. Simulation results show a continuous operation of the antenna system in the frequency band 6.9-13.5 GHz. However, measured results show that the pair of the antennas has not been fabricated properly and at

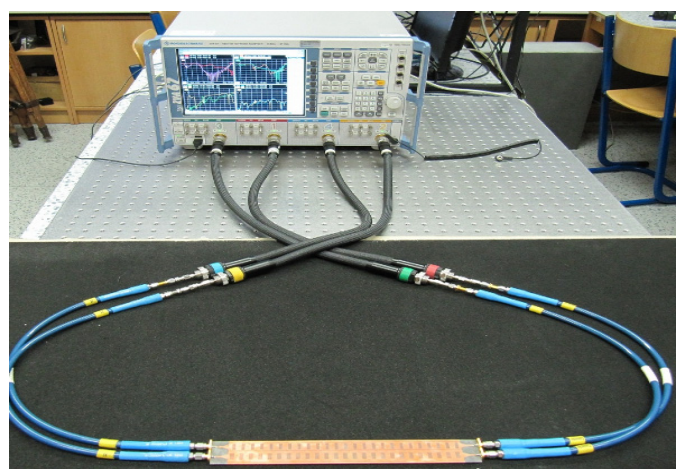

Fig. 6. Photograph of the fabricated system composed of a pair of CRLH SIW lines.

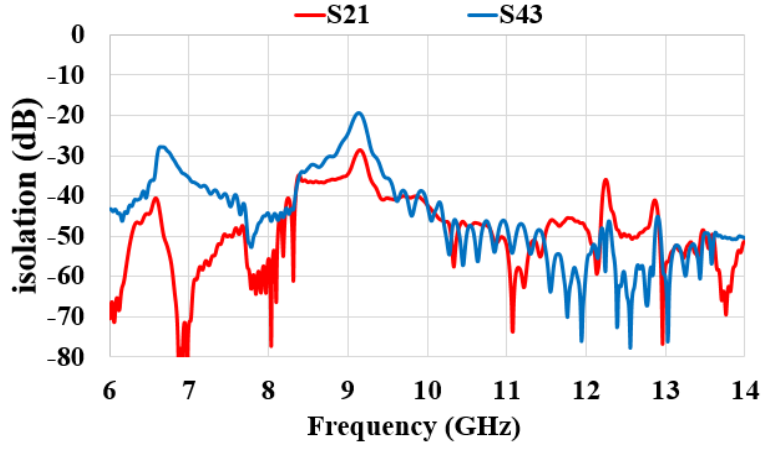

Fig. 7. Simulated isolation results between port 2 and port 1 and between port 4 and port 3 of the proposed pair of SIW CRLH transmission lines.

both areas of broadside radiation, they show stop bands [17] that have not been revealed via simulation. The appearance of the stop band is very sensitive to the dimensions of the fabricated structures. Additionally, the matching of measured $S_{11}$ are slightly high, especially in the left hand regions. This can be attributed to the mismatch of SMA connectors that are not considered in the simulation.

The superposition of the two space leaky waves was measured in an anechoic chamber at different frequencies. The two lines were simultaneously fed by the ZVA67 analyzer with a $180^{\circ}$ phase shift. The ZVA40 analyzer received transmitted signal from the system. Moreover, a DHR20 antenna was used for the test [18]. Figure 9 compares the simulated and measured normalized power patterns at some particular frequencies: when the first line is only radiating, when both lines are radiating and when the second line is only radiating, at $f=7.8 \mathrm{GHz}, f=9.4 \mathrm{GHz}$ and $f=12.5 \mathrm{GHz}$, respectively. A good agreement between both the measured and simulated data is obtained. This verifies the proposed complex variation of the two space leaky wave field. The measured directions of radiation maxima at particular frequencies were compared with the theoretical analysis in Fig. 5 (7) and (8). The fit with angles obtained from the simplified analysis is very good. More details of the radiation behavior are illustrated in Tab. 3 . Figure 10 shows simulated radiation patterns in the $\mathrm{H}$ plane. The angle $\theta$ is here set at the direction of the maximum radiation at each frequency. Plots show only one main lobe in this plane that is required.

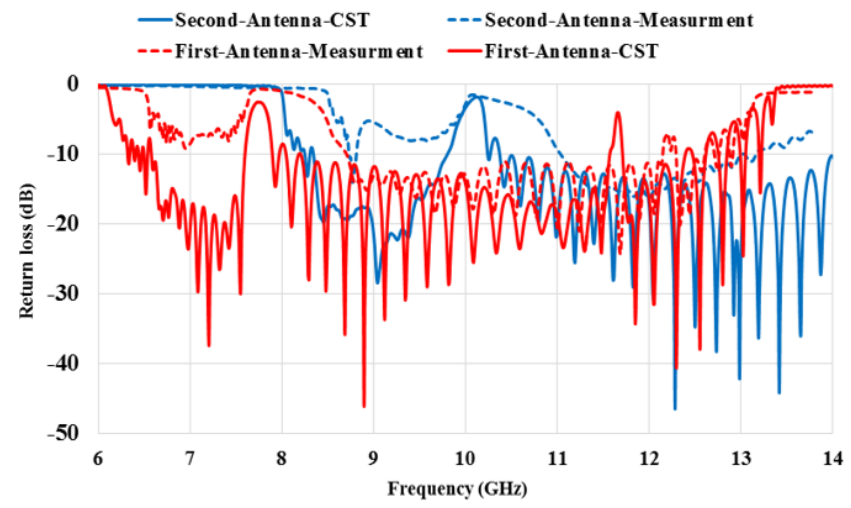

Fig. 8. Simulated and measured $S_{11}$ of the proposed structure. 


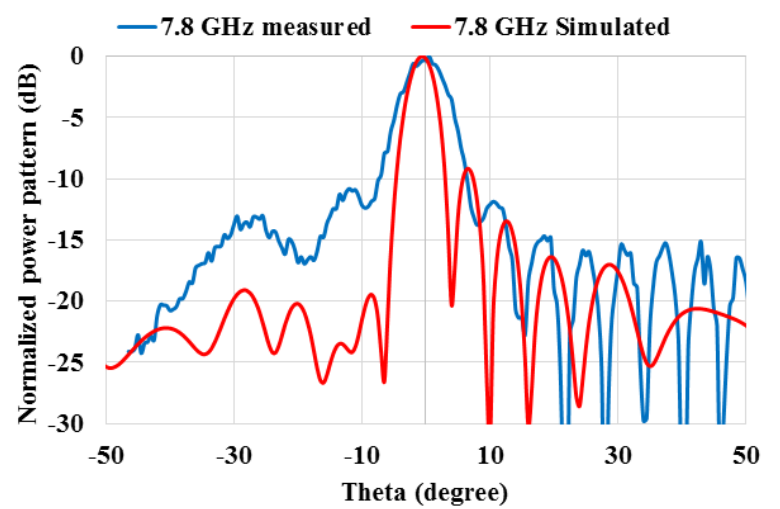

(a)

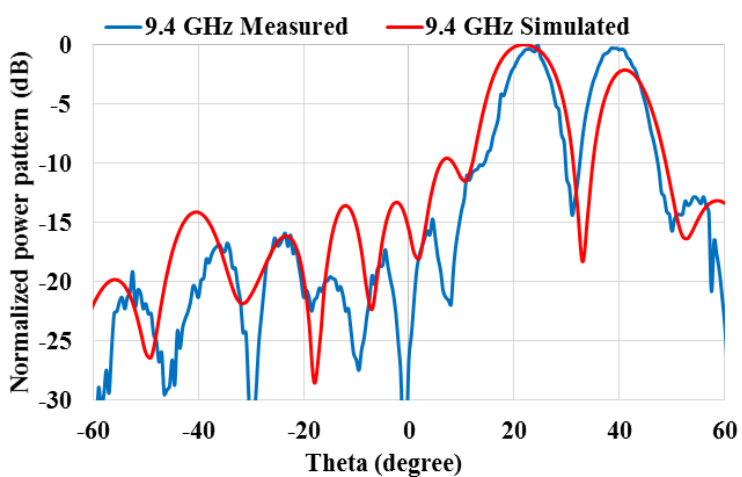

(b)

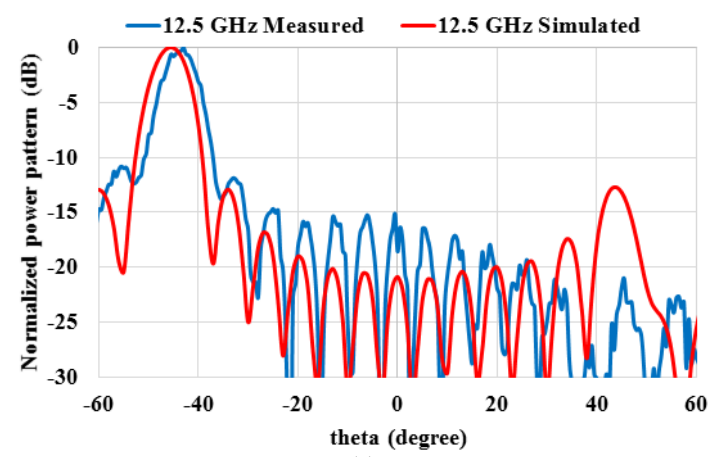

(c)

Fig. 9. Normalized power patterns, measurement vs. simulation at (a) $f=7.8 \mathrm{GHz}$ (when the first line is only radiating); (b) $f=9.4 \mathrm{GHz}$ (when both lines are radiating); (c) $f=12.5 \mathrm{GHz}$ (when the second line is only radiating); (blue line: measurement; red line: simulation).

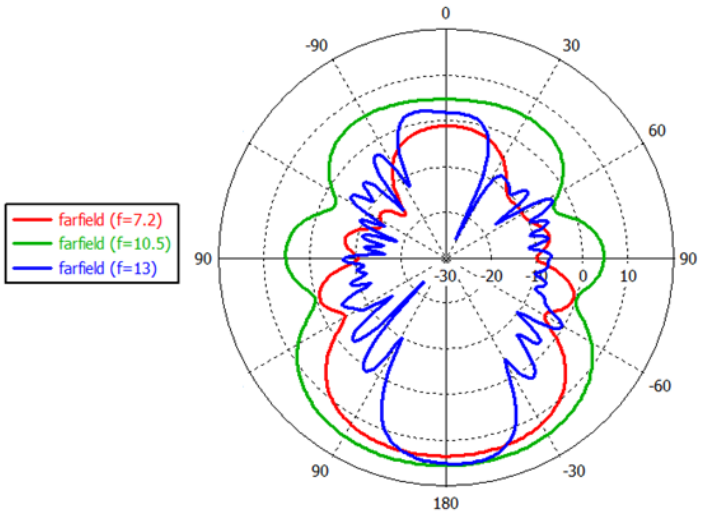

Phi / Degree vs. dB

Fig. 10. Simulated H-plane radiation patterns at $f=7.2 \mathrm{GHz}$, $f=10.5 \mathrm{GHz}$ and $f=13 \mathrm{GHz}$.

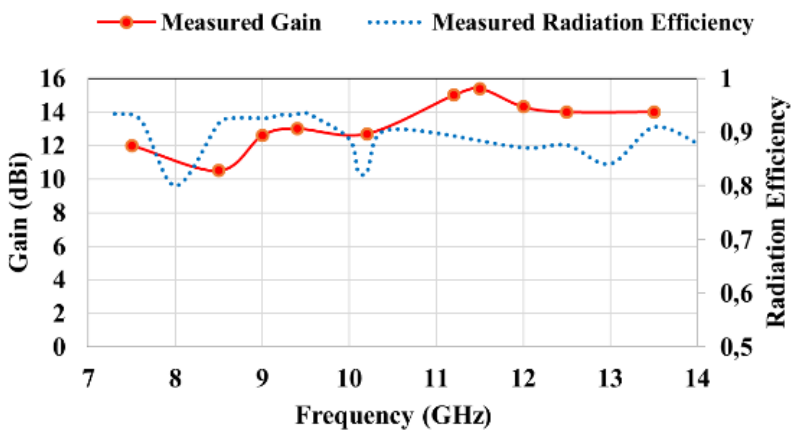

Fig. 11. Measured gain and radiation efficiency of the proposed system.

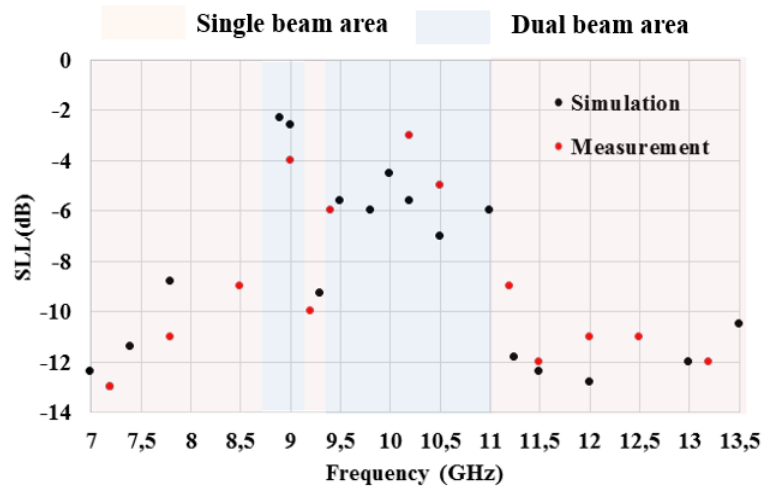

Fig. 12. Measured and simulated Side Lobe Level of the proposed system.

\begin{tabular}{|c|c|c|c|}
\hline Frequency band $(\mathbf{G H z})$ & $\boldsymbol{\beta}_{\mathbf{1}}$ of the first CRLH line & $\boldsymbol{\beta}_{\mathbf{2}}$ of thefirst CRLH line & Main beam numbers \\
\hline $\mathbf{6 . 9 - 7 . 7}$ & $\beta_{1}<0$ & Not radiating & One beam \\
\hline $\mathbf{7 . 8}$ & $\beta_{1}=0(\theta=0)$ & Not radiating & One beam \\
\hline $\mathbf{7 . 9 - 8 . 9}$ & $\beta_{1}>0$ & Not radiating & One beam \\
\hline $\mathbf{8 . 9 - 9 . 3}$ & $\beta_{1}>0$ & $\beta_{2}<0$ & Two beams \\
\hline $\mathbf{9 . 3}$ & \multicolumn{2}{|c|}{$\beta_{1}=-\beta_{2}$} & One beam \\
\hline $\mathbf{9 . 3 - 1 0 . 1}$ & $\beta_{1}>0$ & $\beta_{2}<0$ & Two beams \\
\hline $\mathbf{1 0 . 2}$ & $\beta_{1}>0$ & $\beta_{2}=0(\theta=0)$ & Two beams \\
\hline $\mathbf{1 0 . 3 - 1 1}$ & $\beta_{1}>0$ & $\beta_{2}>0$ & Two beams \\
\hline $\mathbf{1 1 - 1 3 . 5}$ & Not radiating & $\beta_{2}>0$ & One beam \\
\hline
\end{tabular}

Tab. 3. Steering behavior of the pair of SIW CRLH LWA. 


\begin{tabular}{|c|c|c|c|c|c|c|}
\hline & Antenna type & $\begin{array}{c}\text { Impedance frequency } \\
\text { band (GHz) }\end{array}$ & $\begin{array}{l}\text { Maximum } \\
\text { Gain (dB) }\end{array}$ & $\begin{array}{c}\text { Broadside } \\
\text { radiation }(\theta=0)\end{array}$ & Scanning type & $\begin{array}{c}\text { Beam scanning } \\
\text { range }\end{array}$ \\
\hline [6] & Microstrip LWA & $6.92-8.7$ & 12.7 & no & $\begin{array}{c}\text { Symmetrical dual beams } \\
\text { at } \varphi \text { direction }\end{array}$ & $\begin{array}{l}\left(75^{\circ} ; \pm 48^{\circ}\right) \\
\text { to }\left(38^{\circ} ; \pm 60^{\circ}\right)\end{array}$ \\
\hline [7] & Active LWA & $9-11.5$ & Not reported & no & $\begin{array}{c}\text { Asymmetrical dual } \\
\text { beams }\end{array}$ & $\begin{array}{c}\left(24^{\circ} ; 46^{\circ}\right) \\
\left(128^{\circ} ; 150^{\circ}\right)\end{array}$ \\
\hline [8] & $\begin{array}{l}\text { Triple periodic } \\
\text { microstrip LWA }\end{array}$ & $\begin{array}{l}\text { 3-8: with two strong stop } \\
\text { band at } 4 \text { and } 7.8\end{array}$ & -0.8 & no & $\begin{array}{c}\text { Symmetrical and } \\
\text { asymmetrical dual } \\
\text { beams }\end{array}$ & $\begin{array}{c}\left(36^{\circ} ; 72^{\circ}\right) \\
\left(-34^{\circ} ;-46^{\circ}\right) \\
\end{array}$ \\
\hline This work & $\begin{array}{l}\text { CRLH SIW LWA } \\
\text { system }\end{array}$ & $\begin{array}{l}6.9-13.5 \\
\text { (with two stop bands } \\
\text { around } 7.8 \text { and } 10.2 \text { ) }\end{array}$ & 15.2 & yes & $\begin{array}{c}\text { Single beam and } \\
\text { asymmetrical dual } \\
\text { beams }\end{array}$ & $\begin{array}{l}\left(-50^{\circ} ; 72^{\circ}\right) \\
\left(-73^{\circ} ; 62^{\circ}\right)\end{array}$ \\
\hline
\end{tabular}

Tab. 4. Comparison between proposed and in the literature reported dual beam antennas.

The measured gain and radiation efficiency of the system are plotted in Fig. 11. The observed results show that a high gain value is obtained in the entire impedance bandwidth and a maximum of $15.8 \mathrm{~dB}$ is detected at 11.4 GHz. In addition, high radiation efficiency is calculated with an average value of $90 \%$. Those results prove the reliability of the proposed system. Simulated and measured results of side lobe level (SLL) in some particular frequencies over the radiating frequency band are shown in Fig. 12. It can be noticed that low SLL is obtained in the areas where only one main beam is steered and it increases with the appearance of the second radiating beam. Moreover, simulated results correspond well to the measured ones.

Table 4 provides the performance comparison between the proposed work and other designs taken from literature. It is very obvious that the work presented in this paper has a wider band of operation and scanning range as well as a higher maximum gain value than most previous studies.

\section{Conclusion}

In this paper, the superposition of space leaky waves that are excited on the CRLH SIW line system is originally presented. The proposed structure exhibits a complex beam steering behavior over a wide frequency band. A brief theoretical analysis is conducted to prove the idea of the design. The theoretical and measurement results were compared and a good agreement has been revealed. An asymmetrical dual beam steering behavior of leakage field distribution over the frequency band from 6.9 to 13.5 GHz has been obtained with a wide band of scanning range from $-72^{\circ}$ to $+73^{\circ}$. The proposed structure is suitable for smart systems which can be used to monitor a space with a complex geometry and for beam tracking systems as well.

\section{Acknowledgments}

This work was supported by the Grant Agency of the Czech Republic under Project 17-00607S.

\section{References}

[1] LIU, J., JACKSON, D., LONG, Y. Substrate integrated waveguide (SIW) leaky-wave antenna with transverse slots. IEEE Transactions on Antennas and Propagation, 2012, vol. 60, no. 1, p. 20-29. DOI: 10.1109/TAP.2011.2167910

[2] CASSIVI, Y. PERREGRINI, L., ARCIONI, P., et al. Dispersion characteristics of substrate integrated rectangular waveguide. IEEE Microwave and Wireless Components Letters, 2002, vol. 12, no. 9 , p. 333-335. DOI: 10.1109/LMWC.2002.803188

[3] XU, F., WU, K. Numerical multimode calibration technique for extraction of complex propagation constants of substrate integrated waveguide. In IEEE MTT-S International Microwave Symposium Digest, 2004, vol. 2, p. 1229-1232. DOI: 10.1109/MWSYM.2004.1339210

[4] RABAANI, K., BOULEJFEN, N. Characteristic impedance and propagation constant assessment of substrate integrated waveguide transmission line. In 2016 11th International Design \& Test Symposium (IDT). Hammamet (Tunisia), 2016. DOI: 10.1109/IDT.2016.7843054

[5] LI, Y., XUE, Q., YUNG, E. K.-N., et al. Dual-beam steering microstrip leaky wave antenna with fixed operating frequency. IEEE Transactions on Antennas and Propagation, 2008, vol. 56, no. 1, p. 248-252. DOI: 10.1109/TAP.2007.913168

[6] KARMAKAR, D. K., ESSELlE, K. P., BIRD, T. S. Wideband microstrip leaky-wave antennas with two symmetrical side beams for simultaneous dual-beam scanning. IEEE Transactions on Antennas and Propagation, 2016, vol. 64, no. 4, p. 1262-1269. DOI: 10.1109/TAP.2016.2529646

[7] WANG, C. J., JOU, C. F., WU, J. J. A novel two-beam scanning active leaky-wave antenna. IEEE Transactions on Antennas and Propagation, 1999, vol. 47, no. 8, p. 1314-1317. DOI: $10.1109 / 8.791949$

[8] MA, Z. L., JIANG, L. J. One-dimensional triple periodic dualbeam microstrip leaky-wave antenna. IEEE Antennas and Wireless Propagation Letters, 2015, vol. 14, p. 390-393. DOI: 10.1109/LAWP.2014.2365394

[9] MACHAC, J., POLIVKA, M., ZEMLYAKOV, K. A dual band leaky wave antenna on a CRLH substrate integrated waveguide. IEEE Transactions on Antennas and Propagation, 2013, vol. 61, no. 7, p. 3876-3879. DOI: 10.1109/TAP.2013.2256097

[10] DONG, Y., ITOH, T. Substrate integrated composite right/lefthanded leaky-wave structure for polarization flexible antenna application. IEEE Transactions on Antennas and Propagation, 2012, vol. 60, no. 2, p. 760-771. DOI: 10.1109/TAP.2011.2173124

[11] JACKSON, D. R., OLINER, A. A., BALANIS, C. (eds.) Modern Antenna Handbook. Hoboken, NJ, USA: Wiley, 2008. ISBN-13: 978-0470036341 
[12] MACHAC, J., LORENZ, P., SAGLAM, M., et al. Substrate integrated waveguide leaky wave antenna radiating from a slot in the broad wall. In 2010 IEEE MTT-S International Microwave Symposium. Anaheim (CA, USA), May 2010, p. 5-8. DOI: 10.1109/MWSYM.2010.5517997

[13] POZAR, D. M. Microwave Engineering. $3^{\text {rd }}$ ed. Hoboken, NJ: Wiley, 2005. Ch. 8: Microwave filters. ISBN: 9780471644514

[14] DONG, Y., ITOH, T. Composite right/left-handed substrate integrated waveguide and half-mode substrate integrated waveguide. In 2009 IEEE MTT-S International Microwave Symposium Digest. Boston (USA), 2009, p. 49-52. DOI: 10.1109/MWSYM.2009.5165629

[15] WU, K., DESLANDES, D., CASSIVI, Y. The substrate integrated circuits - a new concept for high frequency electronics and optoelectronics. In 6th International Conference on Telecommunications in Modern Satellite, Cable and Broadcasting Service TELSKS 2003. Nis (Yugoslavia), 2003, vol. 1, p. 1-8. DOI: 10.1109/TELSKS.2003.1246173

[16] DONG, Y., ITOH, T. Composite right/left-handed substrate integrated waveguide and half mode substrate integrated waveguide leaky-wave structures. IEEE Transactions on Antennas and Propagation, 2011, vol. 59, no. 3, p. 767-775. DOI: 10.1109/TAP.2010.2103025

[17] DESLANDES, D. Design equations for tapered microstrip to substrate integrated waveguide transitions. In 2010 IEEE MTT-S International Microwave Symposium. Anaheim (CA, USA), May 2010, p. 704-707. DOI: 10.1109/MWSYM.2010.5517884

[18] www.rfspin.cz

\section{About the Authors ...}

Rihem NOUMI was born in Zaghouan, Tunisia. She received the degree in Electrical Engineering from the Fac- ulty of Sciences of Tunis, Tunisia in 2014. She is currently working toward the Ph.D. degree in Electrical Engineering at the same faculty. Her main research interests lie in the LWA antenna designs and SIW technology.

Jan MACHAC was born in Hranice, Czechoslovakia, in 1953. He graduated from the CTU in Prague in 1977. He received his CSc. (Ph.D. equivalent) in Electronics in 1982 at the Institution of Radio Engineering and Electronics of the Czechoslovak Academy of Science in Prague. He received his DrSc. degree in Radio Electronics in 1996 and was named a professor of Electrical Engineering in 2009. His main scientific interests cover investigation of planar passive elements and subsystems of microwave technology, propagation of electromagnetic waves in periodic structures and metamaterials. He is the author or co-author of more than 250 publications in scientific journals, including international ones as well as national conferences.

Ali GHARSALLAH received the degree in Radio Frequency Engineering from the Higher School of Telecommunication of Tunis in 1986 and the Ph.D. degree in 1994 from the Engineering School of Tunis. Since 1991, he has been with the Department of Physics at the Faculty of Sciences of Tunis. Actually, he is a full Professor in Electrical Engineering and the Director of the Engineering studies in the Ministry of Higher Education of Tunisia. His current research interests include smart antennas, array signal processing, multilayered structures and microwave integrated circuits. He has about eighty papers published in scientific journals and more than a hundred conference papers. Professor Gharsallah supervises more than twenty thesis and fifty Masters. 